\begin{tabular}{|c|c|c|c|c|}
\hline $\begin{array}{c}\text { 118SHARE: SOCIAL WORK } \\
\text { JURNAL }\end{array}$ & VOLUME: 7 & NOMOR: 1 & HALAMAN: $1-129$ & $\begin{array}{l}\text { ISSN:2339 -0042 (p) } \\
\text { ISSN: 2528-1577 }(e)\end{array}$ \\
\hline
\end{tabular}

\title{
POTRET ORANG MISKIN DARI PERSPEKTIF KEKUATAN
}

\author{
Oleh \\ Ishartono $^{1}$, Binahayati Rusyidi², Santoso Tri Raharjo ${ }^{3}$ \\ 1. $\quad$ Pusat Studi Kesejahteraan Anak dan Keluarga FISIP-Unpad \\ 2. Pusat Studi Kesejahteraan Anak dan Keluarga FISIP-Unpad \\ 3. Pusat Studi Kewirausahaan Sosial, CSR, dan Pengembangan Masyarakat FISIP-Unpad \\ Email: \\ (kesosish@gmail.com; titi.rusyidi06@gmail.com; santoso.tri.raharjo@unpad.ac.id )
}

\begin{abstract}
"Jika kita berhenti memandang orang miskin sebagai korban atau beban dan mulai mengenali mereka sebagai pengusaha yang tangguh dan kreatif, sebuah dunia baru berpeluang akan terbuka (Prahalad ,2009)
\end{abstract}

\begin{abstract}
Abstrak
Tesis ini dilatarbelakangi oleh permasalahan kemiskinan yang masih saja menjadi beban dunia. Sudah banyak upaya untuk menanggulanginya. Sudah banyak penelitian untuk mengkajinya. Namun upaya dan kajian itu pada umumnya memandang kemiskinan dari perspektif masalah. Tesis ini mengkaji kemiskinan dari perspektif kekuatan. Perspektif ini meyakini bahwa setiap individu mempunyai kekuatan. Penjabaran perspektif kekuatan dalam tesis ini menggunakan konsep yang dikembangkan oleh Clay Graybeal yaitu Resources, Options, Possibilities, Exceptions, dan Solutions (ROPES).

Kajian ini menggunakan pendekatan kualitatif dengan jenis penelitian deskriptif. Pendekatan ini digunakan karena penggalian aspek-aspek kekuatan tersebut (ROPES) memerlukan deskripsi yang mendalam. Subyek penelitian ini adalah orang miskin yang menjadi peserta Program Keluarga Harapan (PKH) di Desa Hegarmanah, Kecamatan Jatinangor, Kabupaten Sumedang. Informannya adalah 4 orang peserta PKH dan 3 orang tokoh masyarakat yang ditentukan secara purposive. Teknik pengumpulan yang digunakan adalah wawancara mendalam.
\end{abstract}

\section{Kata Kunci: Kemiskinan, Perspektif Kekuatan}

\section{Pendahuluan}

Salah satu masalah sosial yang sudah berabad-abad tak kunjung terpecahkan hingga saat ini adalah masalah kemiskinan. Secara statistik hingga saat ini masih ada ratusan juta penduduk dunia ini yang berada di bawah garis kemiskinan. Secara politis PBB tahun 2000 memfasilitasi terselenggaranya Millenium Summit yang menghasilkan deklarasi MDGs. Untuk 2015-20130 PBB memfasilitasi pertemuan negara-negara anggotanya dan menghasilkan deklarasi Sustainable Development Goals (SDGs). Ini memberikan 
indikasi bahwa kemiskinan masih merupakan permasalahan yang menjadi perhatian serius dunia. Di tingkat nasional, Indonesia sendiri juga memandang kemiskinan ini sebagai permasalahan yang serius, sehingga tahun 2010 pemerintah mengeluarkan program Percepatan Penanggulangan Kemiskinan dan membentuk Tim Nasional Percepatan Penanggulangan Kemiskinan (TNP2K) yang dipimpin langsung oleh Wakil Presiden.

Pekerjaan Sosial adalah satu profesi yang sudah berabad-abad pula terlibat dalam penanganan orang miskin. Secara tradisional Pekerjaan Sosial menggunakan problem based perspective dalam keterlibatannya menangani orang-orang miskin. Artinya perhatian penanganan kemiskinan difokuskan pada penanganan permasalahan atau kelemahankelemahan yang dihadapi orang miskin. Pada tiga dasa warsa terakhir ini muncul strengths based perspective di kalangan praktisi Pekerjaan Sosial. Perspektif ini mengkritisi perspektif berbasis masalah yang dianggap tidak efektif menghasilkan perubahan perilaku yang sustainable, bahkan menumbuhkan ketergantungan terhadap sumber-sumber di luar dirinya (Laura Ellis and Elaine Weekse, 2011:1). Kritik lain juga ditujukan terhadap perspektif berbasis masalah ini. Laursen (2003)mengemukakan bahwa pendekatan deficit akan memberikan dampak turunnya motivasi dan aspirasi untuk unggul (dalam Maryann Roebuck, 2007:5).

Jika perspektif berbasis masalah memfokuskan perhatian dan intervensinya pada masalah, maka perspektif berbasis kekuatan justru memfokuskan perhatiannya pada kekuatan dari klien. Perspektif ini meyakini bahwa setiap individu mempunyai kekuatan. bahwa "setiap orang, tanpa kecuali, mempunyai asset internal dan eksternal, kompetensi, serta sumber daya (Dennis Saleeby, 2000, 127), tentu termasuk orang miskin.

Satu hal lagi yang melatarbelakangi penelitian adalah bahwa "Different understandings of poverty, different approaches and ways of thinking about poverty lead to different ways to tackle it". (UN High Commisioner for Human Rights, 2012:1). Pernyataan ini memberikan inspirasi peneliti untuk memandang kemiskinan tidak dari sisi yang selama ini banyak digunakan, baik oleh praktisi maupun teoritisi, baik oleh pemerintah, LSM maupun organisasi internasional. Sisi yang akan digunakan disini adalah sisi kekuatan dari orang miskin. Dengan kata lain peneliti akan meneliti orang miskin dari perspektif kekuatan.

Dengan cara pandang yang berbeda, maka penelitian ini akan memberikan pemahaman yang berbeda terhadap kemiskinan. Memahami kemiskinan dari perspektif kekuatan akan mendapatkan gambaran tentang kekuatan yang dipunyai oleh orang miskin. Jika pemahaman ini digunakan dalam penanganan kemiskinan, maka pendekatan dan cara berpikir dalam menentukan kebijakan maupun program pengentasan kemiskinan akan berbeda pula. Perbedaan ini terjadi karena dengan menggunakan perspektif kekuatan, arah dari penyusunan kebijakan maupun program adalah mendayagunakan kekuatan atau sumber daya orang miskin, bukan mengatasi kelemahan atau kekuarang orang miskin. Dengan cara pandang yang berbeda, hasil penelitian ini diharapkan dapat dijadikan salah satu bahan masukan untuk pengembangan kebijakan dan program-program pengentasan kemiskinan di masa yang akan datang.

\section{Masalah Kemiskinan}

Bagi Indonesia sendiri kemiskinan masih saja menjadi masalah serius yang dihadapi sejak lama. Seriusnya masalah kemiskinan ini bagi Indonesia dapat dilihat dari kebijakan pemerintah dalam menanggulangi kemiskinan. Ada dua kebijakan pemerintah yang fenomenal dalam penanggulangan kemiskinan. Pertama kebijakan pemerintah yang dikenal dengan Program Inpres Desa Tertinggal (IDT). Program ini merupakan upaya pemerintah dalam penanggulangan kemiskinan secara 
nasional dan terpadu. Bukan upaya nasional yang sektoral, yang sebelumnya dilakukan oleh pemerintah. Program ini dikeluarkan melalui Inpres No. 5 tahun 1993 tentang Peningkatan Penanggulangan Kemiskinan. Pelaksanaan program IDT ini dikoordinasikan oleh Badan Perencanaan Pembangunan Nasional (Bappenas). Ke dua kebijakan pemerintah yang lebih dikenal sebagai Program Percepatan Penanggulangan Kemiskinan. Seperti halnya dengan Program IDT, program ini juga bersifat nasional dan terpadu atau lintas sektoral. Program ini didasari oleh Perpres No. 15 tahun 2010 tentang Percepatan Penanggulangan Kemiskinan. Pelaksanaan program ini dikoordinasikan oleh Tim Nasional Percepatan Penanggulangan Kemiskinan (TNP2K) yang secara nasional diketuai langsung oleh Wakil Presiden. Jika pemerintah pusat mengeluarkan kebijakan nasional, yang terpadu, maka kebijakan ini dapat mengindikasikan seriusnya masalah kemiskinan yang dihadapi Indonesia, apalagi Wakil Presiden sendiri yang memimpin pelaksanaan kebijakan ini.

Secara statistik jumlah penduduk miskin di Indonesia juga dapat dijadikan indikator keseriusan masalah kemiskinan. Pada tahun 2010 jumlah penduduk miskin di Indonesia diperkirakan berjumlah 31,02 juta jiwa (BPS, 2010). Jumlah penduduk miskin (penduduk dengan pengeluaran per kapita per bulan di bawah Garis Kemiskinan) di Indonesia pada Maret 2010 mencapai 31,02 juta (13,33 persen). Jumlah ini turun 1,51 juta dibandingkan dengan jumlah penduduk miskin pada Maret 2009 yang sebesar 32,53 juta (14,15 persen). Meskipun jumlah penduduk miskin di Indonesia menunjukkan kecenderungan menurun, namun secara absolut jumlah penduduk miskin ini masih sangat besar, 31 juta jiwa. Sesuai dengan UUD 1945 negara harus menanggung beban ini. Artinya keberadaan penduduk miskin di Indonesia masih menjadi masalah yang besar.

Permasalahan kemiskinan bukan semata-mata berupa beban Negara untuk memelihara penduduk miskin sesuai amanat UUD 1945. Permasalahan kemiskinan ini menjadi lebih besar karena kemiskinan juga menjadi akar permasalahan berbagai masalah sosial. "It's unquestionable that crime ranks high among the effects of poverty", Causes \& Effects of Poverty On Society, Children \& Violence poverties.org Research for social \& economic development - See more at: http://www.poverties.org/effects-ofpoverty.html\#sthash.lFOQKxdi.dpuf

Published March 2011 - Updated May 2013:8). Bukan hanya kriminalitas, kemiskinan juga dapat mengakibatkan gizi buruk, sehingga rentan terhadap penyakit dan bahkan kematian. Kemiskinan juga dapat menjadi faktor penyebab rendahnya tingkat pendidikan. Jadi sangatlah wajar jika UUD 1945 mengamanatkan agar fakir miskin dipelihara oleh negara

Kemiskinan merupakan salah satu fenomena sosial yang mendapat perhatian dari berbagai disiplin ilmu. Perhatian dari disiplin ilmu ini antara lain berupa pemahaman tentang kemiskinan, dalam bentuk definisi atau pengertian maupun karakteristik kemiskinan, serta faktor-faktor yang terkait dengan kemiskinan. Karena masing-masing disiplin ilmu mempunyai obyek formal dan obyek material, maka masing-masing disiplin ilmu akan mempunyai perspektif yang berbeda dalam memandang dan memahami kemiskinan. Karena perspektif yang berbeda, maka akan diperoleh berbagai definisi dan kerakteristik kemiskinan

Adanya berbagai definisi dan karakteristik tentang kemiskinan ini mengindikasikan bahwa kemiskinan ini multidimensional. Masing-masing disiplin akan memandang, memahami, dan kemudian mendefinisikan serta mendeskripsikan kerakteristik kemiskinan sesuai dengan dimensi yang menjadi fokus perhatian masingmasing disiplin ilmu. Perbedaan pemahaman tentang kemiskinan ini mengakibatkan adanya perbedaan pendekatan dan cara berpikir tentang kemiskinan. Perbedaan-perbedaan ini pada akhirnya akan mengakibatkan terjadinya perbedaan cara dalam menanggulangi kemiskinan. Itulah yang telah terjadi selama ini. 
Masing-masing pendekatan ini tentu mempunyai fokus perhatian yang berbedabeda. Karena fokus perhatiannya berbeda, maka pijakan awal dari tindakan dalam mengatasi masalah kemiskinan ini juga berbeda. Kebijakan maupun program yang dikeluarkan pun dapat berbeda-beda pula. Atas dasar hal tersebut, maka sah saja kemiskinan ini dipandang dari perspektif kekuatan.

\section{Pekerjaan Sosial dan Kemiskinan}

Bagi Pekerjaan Sosial, kemiskinan merupakan "major problem". Sejarah lahirnya profesi Pekerjaan Sosial ini tidak dapat dilepaskan dari upaya mengatasi permasalahan kemiskinan, yang pada awalnya masih dalam bentuk kegiatan charity. Dalam sejarahnya kontribusi Pekerjaan Sosial dalam penanganan kemiskinan diawali dengan kegiatan charity secara individual. Orang-orang membantu orang miskin karena dilandasi sikap charity, amal, berdasarkan ajaran agama. Kegiatan membantu orang miskin ini kemudian berkembang dalam bentuk kegiatan yang terorganisasikan. Muncullah organisasiorganisasi kemasyarakatan yang mengorganisasikan dan menyelenggarakan bantuan-bantuan bagi orang-orang miskin. Pemberian bantuan kepada orang miskin dilakukan secara terorganisasi. Meskipun kegiatan pemberian bantuan kepada orang miskin sudah mengalami perkembangan dalam penyelenggaraanannya, namun masih sematamata didasari oleh motif charity. Di Eropa dan Amerika Serikat organisasi-organisasi kemasyarakatan yang menghimpun para pekerja sosial ini didominasi oleh organisasi yang berbasis keagamaan, terutama gereja. Sampai akhirnya lahirnya Pekerjaan Sosial professional sebagai sebuah profesi. Para pekerja sosial professional ini adalah para aktivis sosial yang dididik dalam pendidikan formal Pekerjaan Sosial. Dari sini dapat terlihat betapa sangat eratnya kaitan permasalahan kemiskinan dengan profesi Pekerjaan Sosial.

\section{Dari Problems Perspective ke Strengths Perspective}

Perspektif berbasis masalah atau problem based perspective ini disebut juga "the deficit approach, the problem-based approach". Perspektif ini digunakan dalam praktik Pekerjaan Sosial sejak "kelahiran" profesi ini. Perspektif ini terus digunakan oleh para Pekerja Sosial dalam menangani masalah sampai dengan munculnya perspektif berbasis kekuatan. Perspektif berbasis masalah adalah cara pandang Pekerja Sosial dalam menangani masalah yang terfokus pada masalah-masalah atau kekurangan dan kebutuhan kliennya. Dengan perspektif ini tindakan-tindakan pertolongan yang dilakukan Pekerja Sosial terfokus pada tindakan untuk mengatasi masalah dan memenuhi kebutuhan kliennya.

Perspektif berbasis masalah ini sering disebut juga "pathologist approach", karena pengaruh pendekatan yang digunakan dalam praktik kedokteran, yang memang menggunakan pendekatan patologis atau "diagnostic approach". Secara historik kelahiran Pekerjaan Sosial sebagai profesi tidak dapat dilepaskan dari pengaruh praktik kedokteran, karena "dibidani" oleh seorang dokter (Mary Richmond). Perspektif berbasis masalah ini kemudian secara tradisional mendominasi praktik pemberian pertolongan yang dilakukan para Pekerja Sosial.

Pada dua dekade terakhir muncul perspektif baru, yaitu "Strengths Perspective". Perspektif ini memfokuskan pandangannya terhadap penyandang masalah pada sisi kekuatan yang ada pada penyandang masalah, bukan pada masalah atau kekurangan. Sebelum istilah perspektif berbasis kekuatan ini digunakan, sudah ada beberapa pendekatan yang sangat mirip dengan perspektif berbasis kekuatan, seperti "development resilience", "healing and wellness", "solution focused therapy", "asset-based community development”. (Saleebey, 2002). Perspektif berbasis kekuatan atau "the strengths-based perspective" itu sendiri mulai digunakan sejak tahun 1980. 
Perspektif ini memandang bahwa "setiap orang mempunyai sumber daya dan kapasitas untuk mengembangkan kehidupan mereka yang belum dimanfaatkan" (Saleeby dalam Graeme Stuart., 2012,1) Dalam melaksanakan intervensi terhadap klien, Pekerja Sosial memfokuskan pada kekuatan yang ada pada klien, daripada masalah, kekurangan, dan hal-hal yang bersifat pathologis (Chapin, 1995; Early \& GlenMaye, 2000; Saleebey, 1992d; Weick et al., 1989, dalam Graeme Stuart, 2012,1)). Treatment yang dilakukan adalah mendayagunakan kekuatan-kekuatan klien yang dihasilkan dari asesmen, bukan mengatasi masalahan klien

Jadi sejak munculnya perspektif tersebut, mulailah terjadi pergeseran perspektif dari perspektif berbasis masalah ke perspektif berbasis kekuatan. Perspektif ini seharusnya juga terjadi dalam penanganan masalah kemiskinan. Sudah saatnya terjadi perubahan cara pandang terhadap orang miskin. Sudah saatnya masalah kemiskinan ini dipandang dari perspektif kekuatan. Perspektif ini meyakini bahwa "setiap orang, tanpa kecuali, mempunyai asset internal dan eksternal, kompetensi, serta sumber daya (Dennis Saleebey, 2000, 127).

"Jika kita berhenti memandang orang miskin sebagai korban atau beban dan mulai mengenali mereka sebagai pengusaha yang tangguh dan kreatif, sebuah dunia baru berpeluang akan terbuka (Prahalad ,2009). Kita sering kali keliru memberikan persepsi terhadap orang miskin. Kita sering kali berpikir bahwa orang-orang miskin itu senantiasa menunggu uluran tangan kita, menunggu bantuan kita, menunggu amal kita, padahal pikiran kita ini tidak selalu benar. "Secara keseluruhan orang miskin tidak mencari amal kita; mereka mencari kesempatan untuk menggunakan keterampilan dan tenaga mereka untuk memperbaiki keadaan mereka" .(A New Paradigm for Poverty Relief, Posted by: john in Books , 2011). Mereka adalah orang-orang yang selalu mencoba berusaha untuk memperoleh sesuatu guna memenuhi kebutuhan hidup mereka. Hanya saja, kemampuan dan kesempatan yang tidak mampu mereka capai menyebabkan secara sasat mata seakan-akan mereka adalah orang-orang yang tidak berdaya, yang hanya dapat menunggu bantuan atau tindakan amal orang lain. Lebih lanjut Prahalad mengemukakan bahwa "orang miskin bukanlah penguras sumber daya dari orangorang kaya di dunia ini. Mereka itu dapat menjadi sumber inovasi dan pada akhirnya justru menjadi mesin perputaran perdagangan global dan kemakmuran"

\section{ROPES}

Bahwa perspektif berbasis kekuatan memandang penyandang masalah dari masalahnya tetapi dari kekuatannya, bukan berarti perspektif ini menyangkal adanya masalah. "It is important to understand the strengths-based approach is not about denying that people do experience problems and challenges and these issues do need to be taken into consideration of a more holistic approach". (Wayne Hammond,2010:1). Dalam bahasa yang lain Saleebey mengemukakan bahwa "perspektif kekuatan bukan berarti meninggalkan sama sekali model medik atau patoologis.Schizophrenia adalah nyata. Kekerasan seksual adalah nyata" (Dennis Saleebey, 2001:233). Demikian pula, kemiskinan itu nyata. Perpsektif berbasis kekuatan tidak menolak adanya kenyataan bahwa orang mengalami kemiskinan. Perspektif ini hanya melihat sisi atau dimensi lain dari penyandang masalah. Perspektif ini hanya melihat sisi lain dari orang miskin.

Penelitian ini merupakan kegiatan asesmen berbasis kekuatan terhadap orang miskin. Penjabaran dari kekuatan ini menggunakan konsep yang telah dikembangkan oleh Clay Graybeal (2001;p237-238) yaitu Resources, Options, Possibilities, Exceptions, dan Solutions (ROPES). Graybeal telah menggunakannya sebagai kerangka acuan dalam melakukan asesmen Pekerjaan Sosial dengan strengths perspective. Resources disini meliputi sumbersumber :Pribadi, Keluarga, Lingkungan sosial,Keorganisasian, dan Komunitas. Sementara itu Options yang dilakukan meliputi 
: Fokus perhatian saat ini, Apa yang dapat diakses saat ini, Apa yang tersedia dan belum dicoba atau digunakan. Sedangkan Possibilities menyangkut Fokus masa depan, Imaginasi, Kreativitas, Visi masa depan, Permainan, serta Gagasan-2 yang belum dilakukan. Exceptions dihadapi meliputi situasi pada Saat masalahnya tidak terjadi, Saat mengalami permasalahan berbeda, Saat sebagian dari hipotesis di masa depan terjadi, dan Perjuangan menjaga keselamat, bertahan, dan terus berjuang. Terakhir adalah Solutions meliputi konstruksi solusi bukan pada pemecahan masalah, solusi yang dapat berjalan, keberhasilan yang sudah dicapai, rencana melanjutkan usaha yang berhasil, hikmah-hikmah yang dialami, rencana tindakan atas hikmah-hikmah yang terjadi.

\section{Potret Orang Miskin}

Hasil penelitian memberikan gambaran bahwa orang miskin yang kebetulan masih berada pada usia produktif selalu berusaha menjaga kesehatan. Mereka juga rajin berolahraga dengan mengikuti kegiatan senam. Tujuannya agar dapat tetap beraktivitas memenuhi kebutuhan keluarga. Mereka juga melakukan rekreasi, meskipun hanya sekedar jalan-jalan ke mal bersama anak. Bersabar dan ikhlas menjalani kehidupan ini memberikan ketenangan dalam menghadapi ketidakmampuan ekonomi. Keluarga menjadi sumber kekuatan dan motivasi untuk bertahan menghadapi permasalahan kemiskinan keluarganya. Anak yang sehat, yang taat pada orang tua, yang rajin sekolah, merupakan sumber semangat untuk bertahan. Kerabat juga memberikan kontribusi yang signifikan dalam mengatasi permasalahan yang dihadapi. Saling menolong di antara kerabat memperingan beban hidup. Kepedulian tetangga menambah ketenangan. Beberapa program pemerintah sebetulnya dapat menambah kekuatannya, namun belum semuanya diakses. Para ibu rumah tangga dari keluarga miskin ini telah memilih untuk fokus mencari penghasilan bagi keluarganya. Kemampuan memanfaatkan situasi atau peluang usaha akibat munculnya pondokan-pondokan mahasiswa, memberikan kesempatan mereka untuk menambah penghasilan keluarga dengan berdagang, menjadi buruh cuci ataupun juru masak mahasiswa pondokan. Sikap masyarakat yang tidak membeda-bedakan statstus ekonomi, ikut memberikan ketenangan bagi orang miskin. Mereka tidak perlu merasa rendah diri, karena masyarakat menghargainya. Kelembagaan yang ada di lingkungannya, seperti PKK, belum memberikan manfaat yang nyata bagi mereka. Sumber-sumber pelayanan dari pemerintah yang ada di desanya sudah memberikan manfaat nyata, seperti Perogram Keluarga Harapan (PKH), Kartu Indonesia Sehat (KIS), Kartu Indonesia Pintar (KIP). Meskipun belum mampu mengentaskan mereka dari kemiskinan, sekurang-kurangnya sudah membantu mereka bertahan hidup.

Setiap keluarga memiliki pilihanpilihan untuk menjalani kehidupan keluarganya. Pilihan-pilihan tersebut dapat dilihat dari pandangan mereka atas masa depan, impian-impian, kreatifitas, visi ke masa depan, kesenangan, atau tentang sesuatu hal yang ingin mereka coba. Pilihan untuk memberikan prioritas pada keberlangsungan perkembangan anak-anaknya, baik pendidikan, ekonomi, maupun kebahagiannya telah memberikan kekuatan dan motivasi untuk terus bertahan dan berjuang. Demikian pula dengan perbaikan ekonomi keluarga, dengan melakukan usaha-usaha untuk meningkatkan penghasilan keluarga. Mereka menginginkan anak-anak mereka kelak memperoleh jodoh terbaik. Beberapa informan bahkan bercita-cita dapat menjalankan ibadah umroh kelak, membuka warung nasi, serta suami yang baik. Rumah yang layak huni juga merupakan impian keluarga. Beberapa informan memiliki keterampilan merias, dan mampu menari tradisional. Selain itu kegiatan berolah raga juga merupakan aktivitas rutin yang biasa dilakukan. Mereka memiliki citacita dan visi untuk memperbaiki kehidupannya, dengan tetap sabar dan tabah menjalaninya.

Beberapa aspek berkenaan dengan pengecualian-pengecualian antara lain asumsi tentang seandainya masalah kondisi miskin 
mereka tidak terjadi, atau kalau masalahnya berbeda, perkiraan asumsi kehidupan mereka di masa depan, dan yang terpenting adalah bagaimana keluarga mereka dapat tetap bertahan menghadapi kemiskinan. Pernikahan usia dini, perceraian dan penikahan berulang, ditenggarai merupakan penyebab timbulnya kemiskinan. Hal yang membuat mereka dapat bertahan hingga saat ini adalah keyakinan yang kuat atas agama, serta keberadaan anakanak merupakan faktor kuat yang membuat mereka bertahan.

Orang miskin juga memiliki alternatifalternatif solusi . Upaya yang telah dilakukan antara lain mengumpulkan modal dari penghasilannya sehari-hari. Tujuannya untuk berwirausaha di kemudian hari, seperti misalnya membuka warung nasi, warung kelontong, maupun menjadi pedagang kaki lima agar bisa membantu suaminya bekerja. Selain itu mereka berupaya meningkatkan keterampilan tata rias, kemampuan memasak untuk membuka warung nasi. Selain itu juga tetap memelihara kesehatan keluarga.

\section{Penutup}

Telah dikemukakan bahwa perspektif kekuatan ini didasari suatu prinsip bahwa setiap individu itu mempunyai kekuatan, demikian juga dengan keluarga miskin. Berbagai kekuatan telah digali pada keluarga miskin ini. Dengan menggunakan konsep ROPES dari Clay Graybeal penelitian ini telah menemukan kekuatan tersebut.

Penggunaan perspektif kekuatan bukan serta merta meniadakan permasalahan. Perspektif ini hanya merupakan cara memandang suatu permasalahan dari sisi kekuatan. Penggunaan perspektif kekuatan dalam mengkaji kemiskinan, tidak serta merta meniadakan kemiskinan tersebut.

Meskipun berbagai kekuatan telah ditemukan, namun pada kenyataannya saat ini mereka miskin. Hal dapat terjadi karena kekuatan-kekuatan yang ada pada mereka itu tidak atau belum didayagunakan, baik oleh mereka sendiri maupun oleh para pengelola dan pelaksana program-program pengentasan kemiskinan. Mengapa kekuatan-kekuatan itu tidak didayagunakan? Karena programprogram pengentasan kemiskinan selama ini menggunakan "problem based perspective", sehingga perhatian dan intervensinya terfokus pada permasalahan, kekurangan, atau kelemahan yang ada pada mereka untuk diatasi. Dengan perspektif kekuatan ini diharapkan akan ada perubahan kebijakan dalam mengentaskan masalah kemiskinan ini.

Sasaran dari penggunaan perspektif kekuatan dalam memecahkan masalah (kemiskinan) adalah mendayagunakan kekuatan yang ada pada penyandang masalah. Dengan demikian, implikasi dari hasil penelitian ini adalah mendayagunakan kekuatan-kekuatan yang pada pada orang miskin tersebut. Dalam kasus orang miskin yang menjadi peserta Program Keluarga Harapan (PKH), maka tanggung jawab mendayagunakan kekuatan-kekuatan yang ada pada peserta PKH ini dapat dibebankan kepada para Pendamping PKH.

Para pendamping $\mathrm{PKH}$ ini perlu diberi pelatihan pengembangan perspektif kekuatan. Mereka perlu melakukan asesmen ulang terhadap keluarga-keluarga miskin peserta PKH. Hasil asesmen berbasis kekuatan ini dijadikan pijakan untuk menyusun programprogram dengan tujuan mendayagunakan kekuatan-kekuatan yang ditemukan untuk mengatasi masalah kemiskinan mereka.

\section{DAFTAR PUSTAKA}

Graybeal, Clay, 2001, Strengths-Based Social Work Assessment: Transforming the Dominant Paradigm, Families Society, The Journal of Contemporary Human Services, Vol 82, No. 3.

Laura Ellis and Elaine Weekse, 2011, Why Use a Strengths-Dede Approach Instead of a Deficit-Based Approach?, www.mtroyal.ca/cs/groups/ public/.../pdf _why_strengths_not_deficit.pdf 


\begin{tabular}{|c|c|c|c|c|}
\hline $\begin{array}{c}\text { 118SHARE: SOCIAL WORK } \\
\text { JURNAL }\end{array}$ & VOLUME: 7 & NOMOR: 1 & HALAMAN: $1-129$ & $\begin{array}{l}\text { ISSN:2339 -0042 }(p) \\
\text { ISSN: } 2528-1577 \\
(e)\end{array}$ \\
\hline
\end{tabular}

Maryann Roebuck,2007, The Strength-Based Approach : Philosophy and Principles for Practice,

Raharjo, ST. 2015. "Pekerjaan Sosial Generalis, Suatu Pengantar Bekerja Bersama Organisasi dan Komunitas", Edisi Revisi Buku, Unpad Press,

Raharjo, ST. 2015. "Dasar Pengetahuan Pekerjaan Sosial”, Buku, Unpad Press

Raharjo, ST., Taftazani, BM., Apsari, NC., Santoso, MB. 2016. "PANDUAN PRAKTIKUM MIKRO (Konseling dan Pengembangan Diri)". Buku. Unpad Press.

Raharjo, ST. 2015. "Assessment dan Wawancara dalam Prakti Pekerjaan Sosial dan Kesejahteraan Sosial”, Edisi Revisi Buku, Unpad Press

Saleebey, Dennis, 1996, Strengths Perspective in Social Work Practice : Extentons and Cautions, National Association of Social Works Inc.

-, 2000, Poer in The People; Strengths and Hope, in Advances in Social Work, Vol, 1 No. 2, Indiana University School of Social Work.

2006, Strengths Perspective in Social Work Practice, 4/e, Allan Bacon 75 Arlington, Boston.

Tammie O’Nei, 2006, Human Rights and Poverty Reduction: Realities, Controversies and Strategies, An ODI Meeting Series (editorial), Overseas Development Institute 2006.

BPS, 2009, Profil Kemiskinan di Indonesia Maret 2009, Berita Resmi Statistik BPS, No. 43/07/Th. XII, 1 Juli 2009 , Jakarta.

2010, Profil Kemiskinan di Indonesia Maret 2010, Berita Resmi Statistik, BPS, No.45/07/Th. XIII, 1 Juli 2010, Jakarta.
Office of the United Nations High Commissioner for Human Rights Principles and Guidelines for Human Rights Approach to Poverty Reduction Strategies, 1991, What Poverty is, http://www.thl.fi/thlclient/pdfs/b8f78a80-ac1d-49ff-a50af6e14fd80dde diunduh 15 januari2015

Office of the United Nations High Commissioner for Human Rights Principles and Guidelines for Human Rights Approach to Poverty Reduction Strategies [online] Available at , http://www.ohchr.org/Documents/Pu blications/ PovertyStrategiesen. pdf > [Accessed 10 January 2012]

Social Work Policy Institute, 2013, Poverty http://www.socialworkpolicy.org research/poverty.html 2feb2013)

The World Bank , 2001, World Development Report 2000/2001, Attacking, (C) 2001 The International Bank for Reconstruction and Development / The World Bank, 1818 H Street, N.W., Washington, D.C. 20433, U.S.A.

United Nations, 1995, World Summit for Social Development, Copenhagen, Denmark, www.un.org/documents/ga/conf166/ aconf166-9.htm, diunduh 25agustus 2015 2013, The Millennium Development Goals Report. New York, 